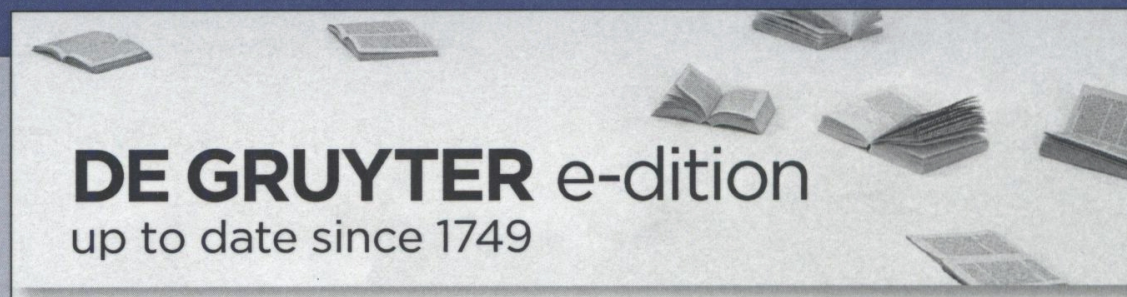

ALL DE GRUYTER PUBLICATIONS

More than 50,000 high-quality publications are available from over 260 years of publishing history.

YOUR CHOICE OF FORMAT

Each title is available in electronic format and in print format as hardcover reprint.

\title{
FULLY DIGITIZED
}

All eBooks offer full-text search, are fully indexed and equipped with DOIs. MARC records are available.

\section{PERPETUAL CONCURRENT USE}

All eBooks can be accessed simultaneously by an unlimited number of an institution's authorized users whether on campus or remote for an unlimited period of time.

\section{PICK AND CHOOSE}

You can order a single eBook title or create your own eBook package. Our sales department will be glad to help you put together a package to match your needs.

\section{RECOMMENDED BY EXPERTS}

International scholars recommend their "best of" titles from De Gruyter's backlist of publications in their special subject areas.

\section{DE DE GRUYTER}

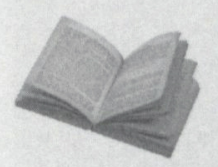

